\title{
"Using the Limitations of Situated Learning Pedagogy to Our Advantage in an Engineering Design Context"
}

Design education in engineering often employs situated-learning based pedagogy, a method of "learning by doing" that focuses on constructing an educational context that mirrors "real world" engineering design situations. As such, many design courses are often built around a team based design project - of varying scope - constructed in a way that mimics real professional work: students are required to research the specific problem, propose and develop a design, and perhaps most importantly, closely document and report on their work. Through this process, students can both learn the fundamentals of design and experience its challenges. Furthermore, by learning how to communicate with fictional or real clients, define problems, deal with constraints, and properly document their designs, students learn how to be engineering professionals [1-2].

However, studies by several critics make clear that students often struggle to understand and respond properly to situated-learning contexts. Despite curriculum designers' attempts to construct as "real" a situation as possible, students remain conscious of the fact that their design project is highly constructed and, ultimately, evaluated within an academic context. It remains a challenge to immerse students completely in the role constructed for them (in which they play engineers and their instructors play their project managers). This uncertainty manifests itself primarily in the project documentation; in the reporting and the presenting of work done, students often have and report difficulty writing about the project appropriately and taking on the voice of a real engineer [3-4].

However, rather than attempt to elide the discrepancy by constructing more realistic situations - a strategy that taxes administrative and financial resources - we could instead take advantage of the pedagogical opportunity presented. By explicitly tackling this discrepancy in class, instructors can confront the need, in engineering work (in both academic and professional environments), for students to engage in appropriate rhetorical behavior, to frame their work in a specific context, and to develop their own professional identities through their writing practice. In this paper, I outline some of the techniques instructors can employ to help students overcome their difficulties with situated-learning design contexts and report on the results of my experience with two design courses, both of which suggest that making students confront the limits of their situated-learning based education can help them develop a more authoritative professional identity.

[1] Artemeva, N. et al. "From Page to Stage: How Theories of Genre and Situated Learning Help Introduce Engineering Students to Discipline-Specific Communication." TCQ. 8.3 (1999): 301-316.

[2] Winsor, D. Writing Like an Engineer: A Rhetorical Education. New York: Lawrence Erlbaum, 1996.

[3] Blakeslee, A. "Bridging the Workplace and the Academy: Teaching Professional Genres through Classroom-Workplace Collaborations." TCQ. 10.2 (2001): 169-192.

[4] Dannels, D. "Learning to be Professional: Technical Classroom Discourse, Practice, and Professional Identity Construction." JBTC. 14.1 (2000): 5-37. 